\title{
Editorial
}

\section{What has gone wrong in stroke research?}

There have been two main approaches to the acute treatment of stroke, thrombolysis and neuroprotection. After a number of disappointing thrombolytic trials using either streptokinase $\mathrm{e}^{1-3}$ or an inappropriately long time-window, ${ }^{4}$ tissue plasminogen activator (t-PA) was demonstrated to improve clinical outcome at three months. ${ }^{5}$ Patients who received t-PA within 3 hours of onset were $30 \%$ more likely to have minimal or no disability at 3 months when compared with placebo. This was at the price of $6.4 \%$ of patients, who received t-PA and developed symptomatic intracerebral haemorrhage, producing a non-statistical benefit in terms of mortality ( $17 \%$ vs $21 \%)$. For many patients, disability is a more important issue than death and t-PA reduces disability, but will cause some deaths from haemorrhage.

Normal cerebral blood flow is approximately $100 \mathrm{ml} / 100$ $\mathrm{g}$ of brain tissue per minute. In cerebral infarction there is a core of tissue with blood flows in the $0-10 \mathrm{ml} / 100 \mathrm{~g} / \mathrm{min}$ range where neuronal death will occur within an hour and the damage is irreversible. Around this is an area of brain called the penumbra, ${ }^{6}$ where blood flow is in the $10-20$ $\mathrm{ml} / 100 \mathrm{~g} / \mathrm{min}$ range. In the penumbra there is electrical failure and large scale release of the excitatory amino acids, glutamate and aspartate. This release of amino acids is associated with calcium influx into the neurones and a cascade of deleterious biochemical events that leads to cell death. The theoretical basis for neuroprotection lies in interrupting this process within the penumbra and reducing the final size of the ischaemic injury. There were initially great hopes for glutamate antagonists, particularly the $N$-methyl-D-aspartate receptor antagonists. ${ }^{7}$ A number of neuroprotectants remain in late clinical development, ${ }^{8}$ but many have fallen by the wayside, either through unacceptable side-effects or lack of efficacy. ${ }^{9}$ The latest, lubeluzole, a NO modifier, produced conflicting results in very similar trials performed on either side of the Atlantic..$^{11}$ Thus far, neuroprotective agents have failed to live up to their promise from animal studies and phase II studies, by not delivering efficacy in phase III.

The early mortality in cerebral ischaemia is predominantly due to swelling of the brain and the development of fatal raised intracranial pressure. This swelling is due to oedema developing in the dead and dying ischaemic areas. A decade ago glycerol was demonstrated to reduce the mortality associated with oedema without increasing the number of disabled survivors. ${ }^{12}$ Even more heroic measures such as decompressive surgery for hemispheric infarction have been tried ${ }^{13}$ with initially encouraging results (mortality reduced from two thirds to a third).

While in the US thrombolysis is standard treatment for those lucky stroke victims who get to hospital early enough and have no changes on computed tomography, in Europe there is no consensus on acute therapy for stroke. The European license for t-PA use in cerebral infarction is currently under consideration. Why have acute treatments for a relatively simple problem of a blocked pipe in the brain been so problematic?

The terminology has seduced us into believing the problem is simple. The term 'stroke' should be exorcised from the medical literature. A stroke is defined as an acute neurological event caused either by cerebral infarction or intracerebral haemorrhage in which symptoms persist for longer than 24 hours or which results in death. The WHO has included subarachnoid haemorrhage as a form of stroke, ${ }^{14}{ }^{15}$ but many authors do not. From a neuroscientific point of view, the term 'stroke' is unsatisfactory in that it includes a number of pathologies whose management and prognosis are different. By using the term there is thus a danger of over simplifying a complex area. Adding qualifiers helps little. Haemorrhagic stroke, which means primary intraparenchymal haemorrhage, is often confused with secondary haemorrhagic transformation of an infarct. The term ischaemic stroke is equivalent to cerebral infarction, but fails to convey the heterogenous nature of the pathology.

When assessing the nature of an acute cerebrovascular event there are several pertinent questions to be answered. First, it must be decided whether it is an infarct or a haemorrhage. If it is a haemorrhage then the underlying cause (hypertensive, arteriovenous malformation, amyloid angiopathy, etc) must be ascertained. If it is an infarct, the first step is to identify the blood vessel concerned. This involves territory (anterior $v s$ posterior) and size (large artery vs arteriole). Ischaemic events are either transient (symptoms resolving within 24 hours) or not. The second step is to infer the probable mechanism; whether it is likely to be due to hypoperfusion or is embolic or thrombotic. The third step, and most important for long-term secondary prevention, is to identify the underlying pathological process, such as atheroma or hyaline degeneration secondary to hypertension (table). The discharge diagnosis on a patient would then be, for example: "cerebral infarction in the middle cerebral artery territory, presumed to be embolic in nature, secondary to atheromatous disease". Such a classification requires clinical acumen and access to neuroimaging. A recent audit in our hospital revealed that the assessment by the admitting doctor went no further than 'stroke' in $60 \%$ of cases (Clinical Audit Department, North Staffordshire Hospital NHS Trust, 1996).

The danger from a clinical point of view of talking about stroke or cerebrovascular disease is that the terms presume a unitary phenomenon. Unsophisticated studies into 'stroke' can produce results that are difficult to apply to individual patients. ${ }^{16}$

Meta-analyses demonstrating that organised stroke unit care reduces death, dependency and the need for institutional care, ${ }^{17}{ }^{18}$ are examples of two heterogenous terms (stroke and stroke unit) held together by $p<0.0001$. What is it about organised care and which patients benefit? As meta-analysis failed to find any sub-group of patients or model of stroke unit care particularly associated with benefit, ${ }^{18}$ one might be tempted to conclude that the

Table Classification of cerebral infarction

\begin{tabular}{lll}
\hline Vessel & Mechanism & Pathological process \\
\hline Carotid & Embolism & Atheroma \\
Middle cerebral & Thrombosis & Hyaline degeneration \\
Anterior cerebral & Hypoperfusion & Migrainous \\
Vertebral & & Hypercoaguable state \\
Basilar & & Atrial fibrillation \\
Posterior cerebral & & Myocardial infarction \\
Arteriol (location) & & Vasculitis \\
\hline
\end{tabular}


advantage was attributable to a general effect, such as staff morale and dedication.

In the general population the word 'stroke' raises feelings of doom and passivity. Only $60 \%$ of the US population over 50 years old realise that a stroke occurs in the brain. ${ }^{19}$ If the potential advantages of thrombolysis and neuroprotective agents are to be realised, patients have to receive medical attention rapidly. In order to raise awareness of the urgent nature of the situation the term 'brain attack' aptly describes the situation without pretending to be a diagnosis.

The term 'stroke' is obscurantist, reductionist, and redundant. It has connotations that are unhelpful to both the general public and the medical profession. Better terms exist that either do not pretend to be a diagnosis (eg, 'brain attack'), or that have some pathophysiological significance. 'Stroke' should be consigned to the dustbin of medical usage.

1 Hommel M, Cornu C, Boutitie F, Boissel JP. Multicentre Acute Stroke Trial Europe: thrombolytic therapy with streptokinase in acute ischaemic stroke. Europe: thrombolytic therapy with

2 Donnan GA, Davis SM, Chambers BR, et al, (Australian streptokinase trial investigators). Streptokinase in acute ischaemic stroke:does time of therapy

3 Multicentre Acute Stroke Trial: Italy (MAST-I) Group. Randomised

3 Multicentre Acute Stroke Trial: Italy (MAST-I) Group. Randomised controlled trial of streptokinase, aspirin, and combination
treatment of acute ischaemic stroke. Lancet 1995;346:1509-14.

4 treatment of acute ischaemic stroke. Lancet 1995;346:1509-14. recombinant tissue plasminogen activator for acute hemispheric stroke. ҰAMA 1995;274:1017-25.

5 The National Institute of Neurological Disorders and Stroke rt-PA Stroke Study Group. Tissue plasminogen activator for acute ischaemic stroke. $N$ Engl F Med 1995;333:1581-7.

6 Paczynski R, Hsu CY, Diringer MN. Pathophysiology of ischaemic injury. In: Fisher M, ed, Stroke therapy. Boston: Butterworth-Heinemann, 1995 ; pp29-64.

7 Kochhar A, Zivin JA, Leyden PD, Mazzarella V. Glutamate antagonist therapy reduces neurological deficits produced by focal central nervous sys-

8 Wahlgren NG. Neuroprotectants in late clinical development - a status Wahlgren NG. Neuroprotectants in

Davis SM, Albers GW, Diener HC, Lees KR, Norris J. Termination of acute Davis SM, Albers GW, Diener HC, Lees KR, Norris J. Terminatio
stroke studies involving selfotel treatment. Lancet 1997;349:32.
Those interested in the management of 'stroke' were lulled into intellectual complacency by an uncritical acceptance of analogies with myocardial infarction. Cerebral infarction is a much more complex process and requires a more sophisticated approach; a preliminary and necessary step is the discarding of simplistic terminology. We can then concentrate on therapeutic interventions in subpopulations defined by pathology and time from onset.

SIMON J ELLIS CAROLINE MATTHEWS

Department of Neurology, Keele University, North Staffordshire Royal Infirmary, Staffs ST4 7LN, UK

Supported by the Neurosciences Trust.

Accepted 19 April 1999

Keywords: stroke

10 Grotta J, Hantson L, Wessel T. The efficacy and safety of lubeluzole in patients with acute ischemic stroke. Stroke 1997;28:205.

11 European and Australian Lubeluzole Ischaemic Stroke Study Group. Multinational randomised controlled trial of lubeluzole in acute ischaemic stroke. Cerebrovasc Dis 1998;8:172-81.

12 Bayer AJ, Pathy MSJ, Newcombe R. Double-blind randomised trial of intravenous glycerol in acute stroke. Lancet 1987;i:405-8.

13 Reike K, Schwab S, Krieger D, et al. Decompressive surgery in space-occupying hemispheric infarction - results of an open, prospective trial. Crit Care Med 1995;23:1576-87.

14 Aho K, Harmsen P, Hatano S, Marquardsen J, Smirnov VE, Strasser T. Cerebrovascular disease in the community: results of a WHO collaborative study. Bull WHO 1980;58:113-30.

15 International Statistical Classification of Diseases and Related Health Problems, Tenth Revision. Geneva: World Health Organisation, 1992; pp 498.

16 Bousser M-G. Aspirin or heparin immediately after stroke? Lancet 1997;349:1564-65.

17 Langhorne P, Williams BO, Gilchrist W, Howie K. Do stroke units save lives? Lancet 1993;342:395-8.

18 Stroke Unit Trialist's Collaboration. Collaborative systematic review of the randomised trials of organized inpatient (stroke unit) care after stroke. BMf 1997;314:1151-9.

19 National Stroke Association. Stroke remains a deadly mystery to many Americans. Be Stroke Smart 1996;13(7):2-3.

Arthur Espie Porritt (1900-1994) was born in Wanganui, New Zealand, son of a surgeon. He was a Rhodes Scholar at Oxford, an Olympic athlete, a surgeon at St Mary's Hospital, London, Sergeant-Surgeon to the Queen, the President of the Royal College of Surgeons (1960), Governor-General of New Zealand (1967) and was made a Life Peer in 1973. He died in London on 1 January 1994. - DG fames 